\title{
Finite element analysis of optimized compound cylinder
}

\author{
Sunil A. Patil \\ Tolani Meritime Institute, Pune - 410507, Maharashtra, India.
}

Accepted 20 January, 2011

\begin{abstract}
The cylindrical vessels are used for storing fluids at high pressure. If the magnitude of the internal/external pressure is closer to the yield strength of the material used, then no thickness of the material will prevent the failure of the vessel. Hence shrink-fitted compound cylinders are used, which can store the fluids at higher pressure closer to the yield stress of the material. Optimally designed compound cylinder has equal maximum hoop stress in both - the inner and outer cylinders. The value of this hoop stress is closer to the value of yield stress of the material used. There are many parameters in the design of compound cylinder. Out of them only a few are important. Three important parameters are chosen for optimization - interface diameter, interference and outside diameter, keeping other parameters such as material, internal diameter, etc constant. The optimization is highly nonlinear and if the number of parameters is large, solution time will be more. Compound cylinders have historically been designed such that the maximum shear stress is equal in each cylinder. This is the optimum condition for yielding of the cylinder, since both cylinders yield at the same pressure. If compound cylinders are subjected to fatigue, this is not the case. A better design criterion is to equate the maximum tensile stress in each cylinder, since the maximum tensile stress controls fatigue crack propagation. I have used maximum tensile stress (Hoop stress) criterion to arrive at the optimum design of compound cylinder. This paper describes the method of determining the optimum dimensions of both the cylinders made of specified material and to withstand a specified internal pressure so that the volume (and weight) is minimum. The results obtained are verified by using ANSYS finite element analysis packages.
\end{abstract}

Key words: Optimum design, compound cylinder, maximum tensile stress, finite element analysis (FEA).

\section{INTRODUCTION}

In the classical design of thick cylinders, if the internal fluid pressure approaches the safe working stress limit of the material, the thickness of the cylinder approaches infinite value. To overcome this difficulty, compound cylinders are used, where one cylinder is shrink fitted on another cylinder. Some researchers (Liu and Zhou, 1994; Lazzarin and Livieri, 1997; Majzoobi et al., 2003; Hojjati and Hassani, 2007).have analyzed the autofrettaged cylinders, which are similar to compound cylinders.

Designing a shrink fit assembly is tricky because the stress developed in the cylinders is a function of internal fluid pressure, shrinkage pressure and the dimensions of the cylinders. Also the shrinkage pressure is a function of the amount of interference and dimensions of the cylinders. That is, unless the shrinkage pressure is known, stresses developed cannot be computed and to compute shrinkage pressure, dimensions of both the cylinders must be known. Hence a cumbersome trial and error method is to be used.

In the optimum design of compound cylinders, the thickness of both the cylinders should be just sufficient to withstand the hoop stresses developed. That means the maximum hoop stress produced in both cylinders should be equal. In this, shrinkage (contact) pressure plays an 
important role.

The shrinkage pressure can be such that the limiting compressive stress is produced in inner cylinder. But when subjected to internal pressure, it causes unequal stresses in both cylinders. That is, in one of the cylinders, the stress can be equal to maximum allowable stress and in other, less than maximum allowable stress.

This paper describes the method of determining the optimum dimensions of both the cylinders made of specified material and to withstand a specified internal pressure so that the volume (and weight) is minimum. The results obtained are verified by using ANSYS finite element analysis packages.

In the classical design of thick cylinder, the thickness (t) of thick cylindrical shell is computed by using various formulae depending upon the type of material used. For ductile material and open type of pressure vessels, Birnie's equation given below is used.

$$
\mathbf{t}:=\mathbf{d}_{1} \cdot\left[\sqrt{\left.\frac{\left[\sigma_{\mathbf{t}}+(1-\mu) \cdot \mathbf{P}\right]}{\left[\sigma_{\mathbf{t}}-(1+\mu) \cdot \mathbf{P}\right]}-1\right]}\right.
$$

As per this equation, if the internal pressure of fluid approaches the tensile strength of the material, the thickness of cylinder tends to infinity. Hence the cylindrical shell is shrink-fitted with another cylinder called a jacket, with certain interference at the interface diameter. Due to shrinkage, a contact pressure (Ps) is developed at the interface. This causes a compressive pre-stress in the inner cylinder and tensile pre-stress in the outer cylinder (jacket). These stresses can be computed by using following equations.

Compressive stress at inner surface of inner cylinder

$\sigma_{\mathrm{t}}:=\mathrm{P}_{\mathrm{s}} \cdot \frac{\left(2 \cdot \mathrm{d}_{2}{ }^{2}\right)}{\left(\mathrm{d}_{2}{ }^{2}-\mathrm{d}_{1}{ }^{2}\right)}$

Tensile stress at inner surface of outer cylinder

$$
\sigma_{\mathrm{t}}:=\mathrm{P}_{\mathrm{s}} \cdot \frac{\left(\mathrm{d}_{3}{ }^{2}+\mathrm{d}_{2}{ }^{2}\right)}{\left(\mathrm{d}_{3}{ }^{2}-\mathrm{d}_{2}{ }^{2}\right)}
$$

When the compound cylinder is subjected to internal fluid pressure $(P)$, it causes tensile (hoop) stress in both the cylinders, which can be computed by -

$$
\sigma_{\mathrm{t}}:=\mathrm{P} \cdot \frac{\mathrm{d}_{1}^{2}}{\left(\mathrm{~d}_{3}^{2}-\mathrm{d}_{1}^{2}\right)} \cdot\left(1+\frac{\mathrm{d}_{3}^{2}}{\mathrm{~d}^{2}}\right)
$$

Both these stresses are superimposed to get the resultant stresses. The other stresses that is, radial and longitudinal stresses are small as compared to hoop stresses. Hence they are not considered. The resultant maximum hoop stresses occur at the inner surfaces of both the cylinders and are given by

(a) At inside surface of inner cylinder $\left(d=d_{1}\right)$

$$
\sigma_{\text {imax }}:=P \cdot \frac{\left(d_{3}{ }^{2}+d_{1}^{2}\right)}{\left(d_{3}^{2}-d_{1}^{2}\right)}-P_{s} \cdot \frac{2 \cdot d_{2}^{2}}{\left(d_{2}{ }^{2}-d_{1}^{2}\right)}
$$

(b) At inside surface of outer cylinder $\left(\mathrm{d}=\mathrm{d}_{2}\right)$

$$
\sigma_{\text {omax }}:=P \cdot \frac{\left(\mathrm{d}_{3}{ }^{2}+\mathrm{d}_{2}^{2}\right)}{\left(\mathrm{d}_{3}{ }^{2}-\mathrm{d}_{1}^{2}\right)} \cdot\left(\frac{\mathrm{d}_{1}{ }^{2}}{\mathrm{~d}_{2}{ }^{2}}\right)+\mathrm{P}_{\mathrm{s}} \cdot \frac{\left(\mathrm{d}_{3}{ }^{2}+\mathrm{d}_{2}^{2}\right)}{\left(\mathrm{d}_{3}{ }^{2}-\mathrm{d}_{2}{ }^{2}\right)}
$$

\section{OPTIMUM DESIGN BASED ON MAXIMUM TENSILE STRESS}

In the optimum design of compound cylinder, the contact pressure plays a very important role. If the maximum contact pressure is used such that limiting compressive stress is produced in the inner cylinder, then the thickness of outer cylinder will be more to keep the tensile stress within limits. Similarly, if minimum contact pressure is used, then thickness of inner cylinder is increased to keep the tensile stress within limits. In either case, the tensile stress developed in both the cylinders will be unequal. So the proper value of contact pressure will produce equal tensile stresses in both the cylinders. This value of contact pressure is computed by equating Equations (5) and (6) as follows.

$$
P \cdot \frac{\left(d_{3}^{2}+d_{1}^{2}\right)}{\left(d_{3}^{2}-d_{1}^{2}\right)}-P \cdot \frac{2 \cdot d_{2}^{2}}{\left(d_{2}^{2}-d_{1}^{2}\right)}=\cdot P \cdot \frac{\left(d_{3}^{2}+d_{2}^{2}\right)}{\left(d_{3}^{2}-d_{1}^{2}\right)} \cdot\left(\frac{d_{1}^{2}}{d_{2}^{2}}\right)+P \cdot \frac{\left(d_{3}^{2}+d_{2}^{2}\right)}{\left(d_{3}^{2}-d_{2}^{2}\right)}
$$

Taking ratios as $\mathrm{c}_{1}=\mathrm{d}_{2} / \mathrm{d}_{1}, \mathrm{c}_{2}=\mathrm{d}_{3} / \mathrm{d}_{2}$ and solving for shrinkage pressure (Ps)

$$
\mathrm{P}_{\mathrm{S}}:=\mathrm{P} \cdot \frac{\left[\frac{\mathrm{c}_{2}^{2} \cdot\left(\mathrm{c}_{1}{ }^{2}-1\right)}{\mathrm{c}_{1}{ }^{2} \cdot \mathrm{c}_{2}{ }^{2}-1}\right]}{\left(\frac{\mathrm{c}_{2}{ }^{2}+1}{\mathrm{c}_{2}{ }^{2}-1}+\frac{2 \cdot \mathrm{c}_{1}{ }^{2}}{\mathrm{c}_{1}^{2}-1}\right)}
$$

To produce the contact pressure which develops equal tensile stresses in both cylinders, the amount of diameter-wise interference required is computed by -

$$
\delta_{1}:=\mathrm{P}_{\mathrm{s}} \cdot \frac{\left[2 \cdot \mathrm{d}_{1} \cdot \mathrm{c}_{1} \cdot\left[\left(\mathrm{c}_{1} \cdot \mathrm{c}_{2}\right)^{2}-1\right]\right]}{\left[\mathrm{E} \cdot\left(\mathrm{c}_{2}{ }^{2}-1\right) \cdot\left(\mathrm{c}_{1}{ }^{2}-1\right)\right]}
$$




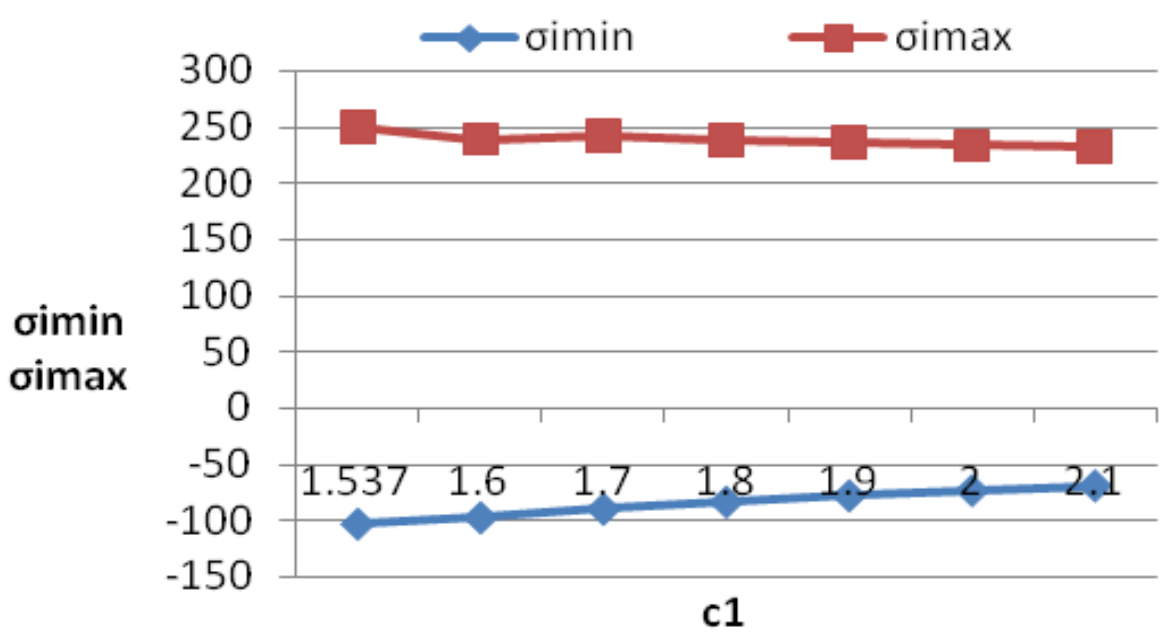

Figure 1. Variation of $\sigma_{i \min }$ and $\sigma_{\text {imax }}$ w.r.t. $c_{1}$.

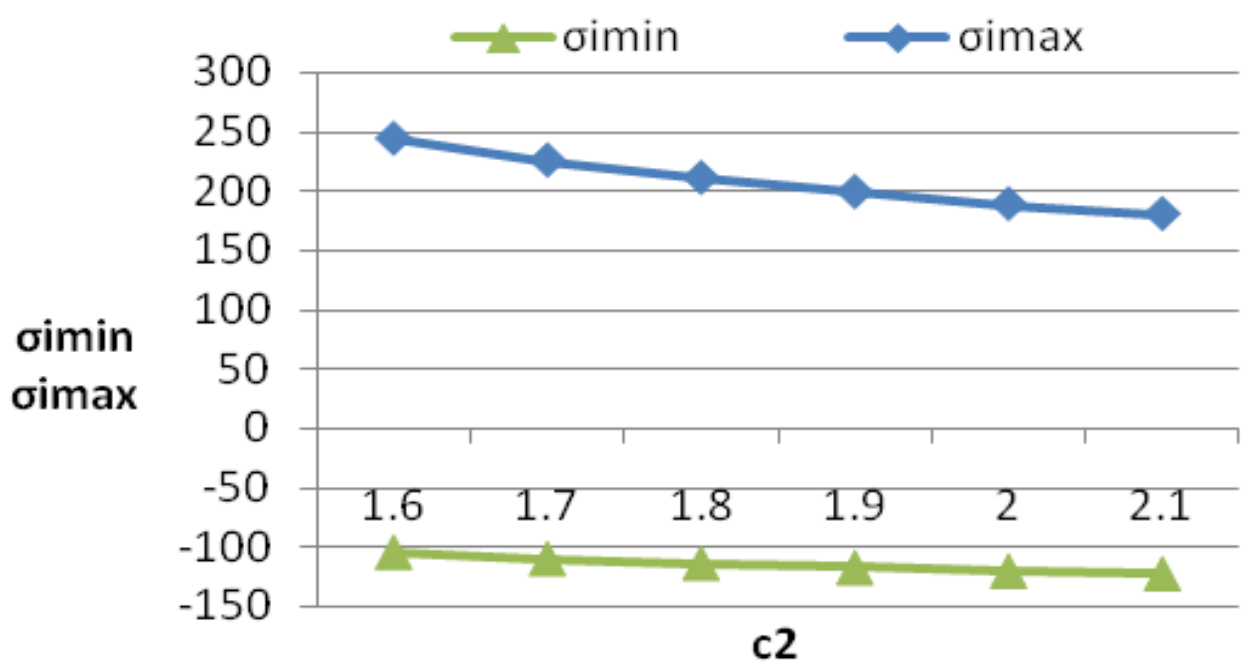

Figure 2. Variation of $\sigma_{i \min }$ and $\sigma_{i \max }$ w.r.t. $\mathrm{c}_{2}$.

It is observed that for a specified thickness of inner cylinder, there exists a certain thickness of outer cylinder which produces equal tensile stresses in both the cylinders. Hence for minimum volume (or weight) of compound cylinder, the thickness of inner cylinder is so chosen that it will give minimum thickness of outer cylinder while keeping the tensile stresses in both cylinders equal and max. It is computed by using any iterative numerical methods.

Generally the inside diameter is dictated by the volume of fluid to be stored. It is computed by using following formula

$d_{1}=(4 V / \pi L)^{1 / 2}$

The inside diameter $\left(d_{1}\right)$ is kept constant at $100 \mathrm{~mm}$. The material for both the cylinders is assumed to be linear isotropic with following properties:

Permissible tensile stress $=250 \mathrm{MPa}$

Modulus of elasticity $=2.1 \times 10^{5} \mathrm{MPa}$

Poisson's ratio $=0.3$
The effect of variation of $c 1, c_{2}$ and interference $\left(\delta_{1}\right)$ on the maximum principal stress in inner cylinder is as shown in Figures 1 to 3 .

The effect of variation of $c_{1}$ and $c_{2}$ on the maximum principal stress in outer cylinder is as shown in the Figures 3 to 6.

It is observed that for a given value of $c_{1}$, there exists a value of $\mathrm{c}_{2}$, where the maximum hoop stress developed in both the cylinders is equal to permissible hoop stress. But the volume (or weight) of compound cylinder is not minimum.

\section{Optimization problem definition}

Given, $P=\sigma_{y}, E, d_{1}=(4 V / \pi L)^{1 / 2}$,

Minimize $f(x)=\pi^{*}\left(d_{3}{ }^{2}-d_{1}{ }^{2}\right) / 4$

In terms of parameters $c_{1}$ and $c_{2}$, 


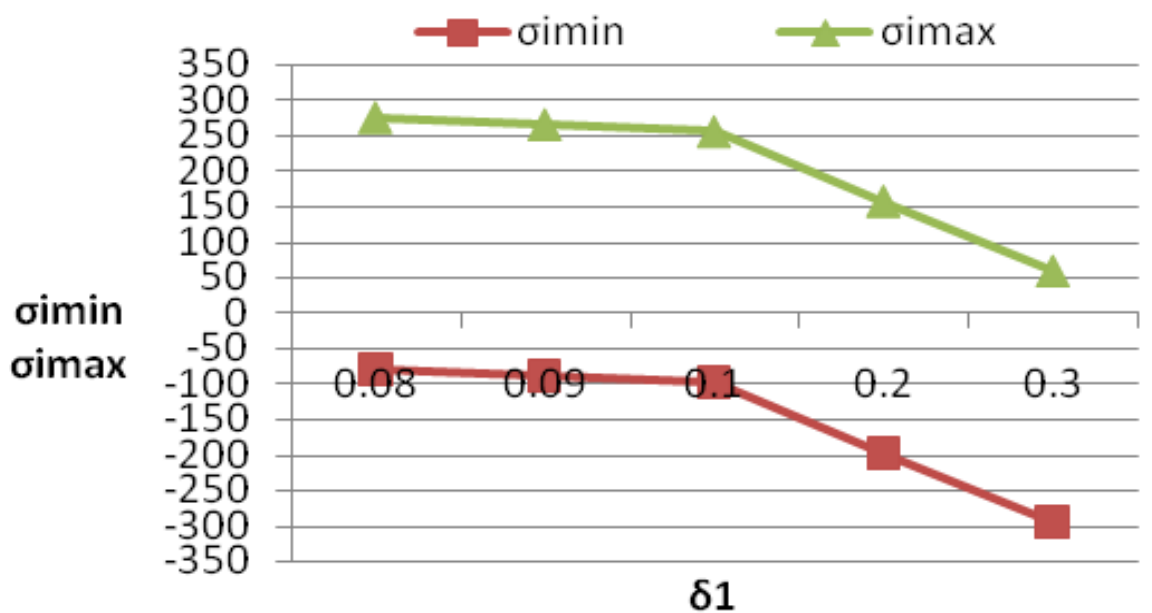

Figure 3. Variation of $\sigma_{i \min }$ and $\sigma_{i \max }$ W.r.t. $\delta_{1}$

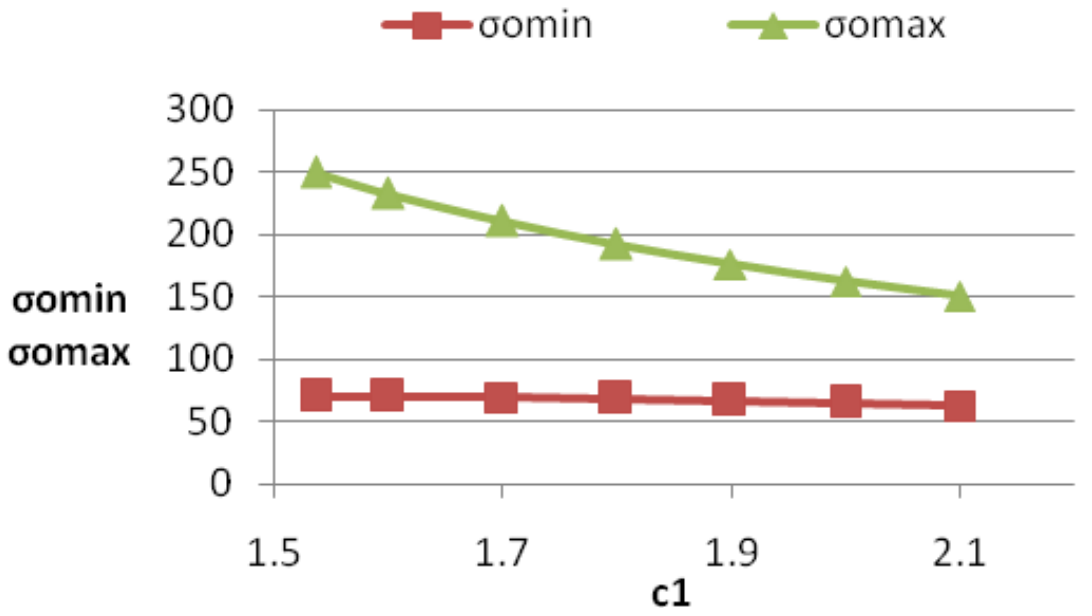

Figure 4. Variation of $\sigma_{o \min }$ and $\sigma_{o \max }$ w.r.t. $c_{1}$.

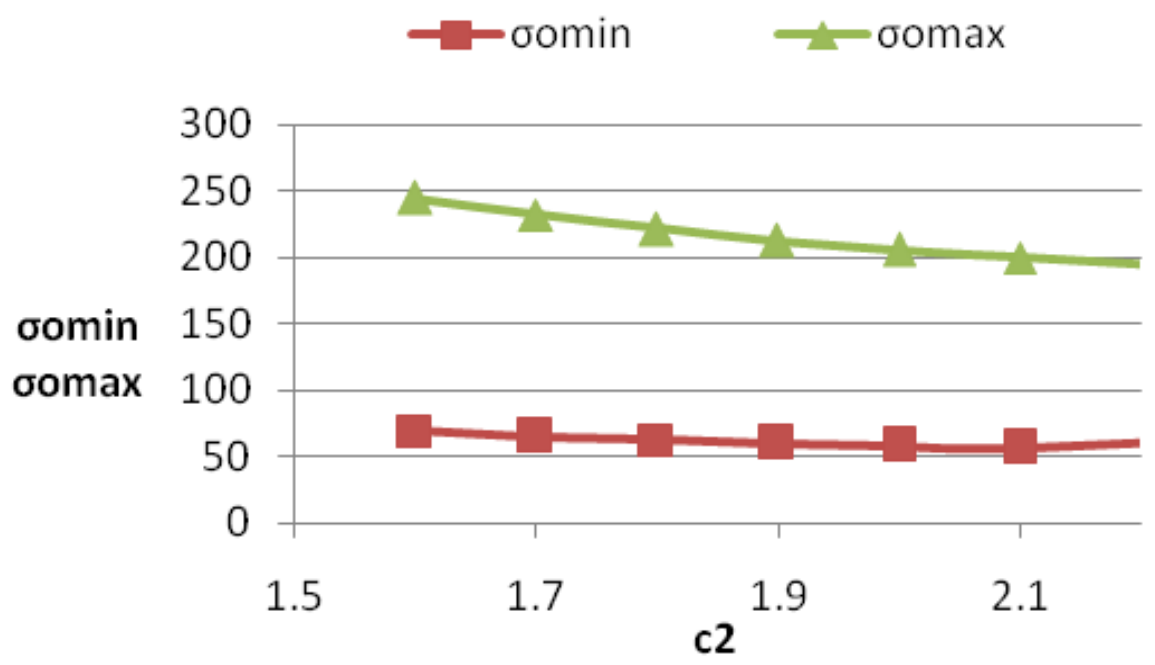

Figure 5. Variation of $\sigma_{o m i n}$ and $\sigma_{o m a x}$ w.r.t. $c_{2}$ 


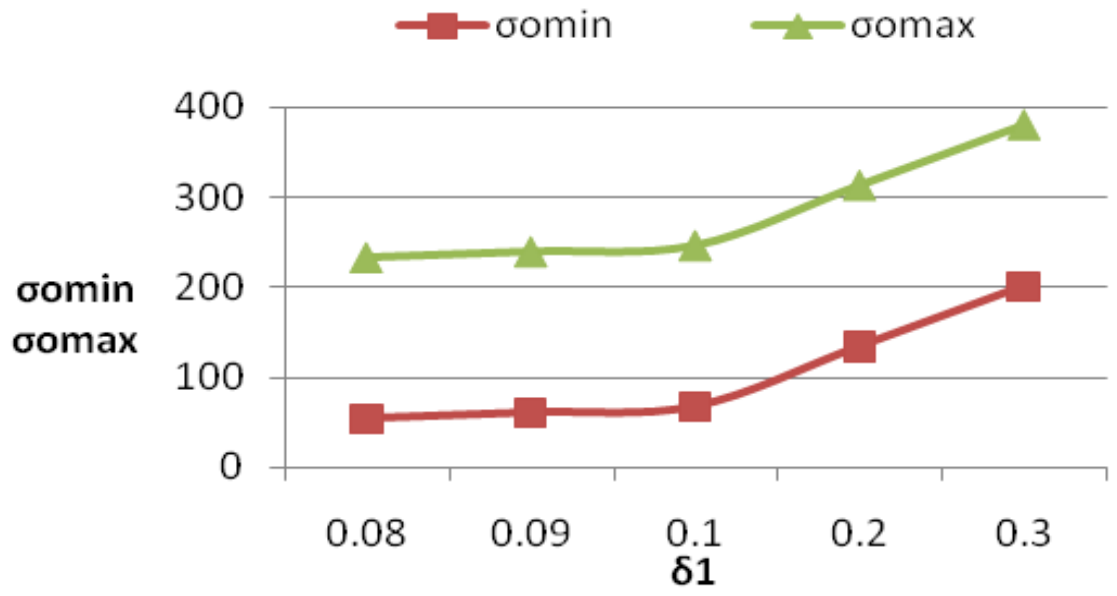

Figure 6. Variation of $\sigma_{o \min }$ and $\sigma_{o m a x}$ w.r.t. $\delta_{1}$.

$f(x)=\pi^{*} d_{1}{ }^{2 *}\left(\left(c_{1} c_{2}\right)^{2}-1\right) / 4$

Subject to constraints:

$$
\begin{gathered}
\mathrm{P} \cdot \frac{\left[\left(\mathrm{c}_{1} \cdot \mathrm{c}_{2}\right)^{2}+1\right]}{\left[\left(\mathrm{c}_{1} \cdot \mathrm{c}_{2}\right)^{2}-1\right]}-\delta_{1} \cdot \frac{\mathrm{E} \cdot\left(\mathrm{c}_{2}{ }^{2}-1\right)}{\mathrm{d}_{1} \cdot\left[\left(\mathrm{c}_{1} \cdot \mathrm{c}_{2}\right)^{2}-1\right]} \cdot \mathrm{c}_{1} \leq \sigma_{\mathrm{y}}, \\
\mathrm{P} \cdot \frac{\left(\mathrm{c}_{2}^{2}+1\right)}{\left[\left(\mathrm{c}_{1} \cdot \mathrm{c}_{2}\right)^{2}-1\right]}+\delta_{1} \cdot \frac{\mathrm{E} \cdot\left(\mathrm{c}_{1}{ }^{2}-1\right)}{2 \cdot \mathrm{d}_{1} \cdot \mathrm{c}_{1} \cdot\left[\left(\mathrm{c}_{1} \cdot \mathrm{c}_{2}\right)^{2}-1\right]} \cdot\left(\mathrm{c}_{2}{ }^{2}+1\right) \leq \sigma_{\mathrm{y}},
\end{gathered}
$$

$\delta_{1}>0$

Parameters to optimize $-c_{1}, c_{2}, \delta_{1}$.

The above set of non-linear equations is solved by using a nonlinear solver available in MS-Excel and the results are as given below.

$c_{1}=1.5522, \quad c_{2}=1.556, \quad \delta_{1}=0.108$.

If $\mathrm{d} 1=100 \mathrm{~mm}$, then by using $\mathrm{c} 1=\mathrm{d}_{2} / \mathrm{d}_{1}, \mathrm{c}_{2}=\mathrm{d}_{3} / \mathrm{d}_{2}$, we obtain

$\mathrm{d}_{2}=155.22 \mathrm{~mm}, \mathrm{~d}_{3}=421.5 \mathrm{~mm}$.

\section{Manual calculations}

The MathCAD worksheet is used to perform the calculations as shown below.

$$
\begin{aligned}
& \mathrm{P}_{\mathrm{S}}=\delta_{1} \cdot \frac{\mathrm{E} \cdot\left(\mathrm{c}_{2}{ }^{2}-1\right) \cdot\left(\mathrm{c}_{1}{ }^{2}-1\right)}{2 \cdot \mathrm{d}_{1} \cdot \mathrm{c}_{1} \cdot\left[\left(\mathrm{c}_{1} \cdot \mathrm{c}_{2}\right)^{2}-1\right]}=30.274 \\
& \mathrm{P}_{\mathrm{S} 1}:=\mathrm{P} \cdot \frac{\left(\mathrm{c}_{2}^{2}-1\right)}{\left(\mathrm{c}_{1}^{2} \cdot \mathrm{c}_{2}^{2}-1\right)}+\mathrm{P}_{\mathrm{S}}=103.804
\end{aligned}
$$

\section{Inner cylinder}

$$
\begin{aligned}
& \sigma_{\text {imax }}=\mathrm{P} \cdot \frac{\left[\left(\mathrm{c}_{1} \cdot \mathrm{c}_{2}\right)^{2}+1\right]}{\left[\left(\mathrm{c}_{1} \cdot \mathrm{c}_{2}\right)^{2}-1\right]}-\mathrm{P}_{\mathrm{s}} \cdot 2 \cdot \frac{\mathrm{c}_{1}^{2}}{\left(\mathrm{c}_{1}^{2}-1\right)}=249.952 \\
& \sigma_{\text {imin }}=-\left[\mathrm{P}_{\mathrm{S}} \cdot 2 \cdot \frac{\mathrm{c}_{1}^{2}}{\left(\mathrm{c}_{1}{ }^{2}-1\right)}\right]=-103.529
\end{aligned}
$$

\section{Outer cylinder}

$$
\begin{aligned}
& \sigma_{\text {omax }}=\mathrm{P} \cdot \frac{\left(\mathrm{c}_{2}{ }^{2}+1\right)}{\left[\left(\mathrm{c}_{1} \cdot \mathrm{c}_{2}\right)^{2}-1\right]}+\mathrm{P}_{\mathrm{S}} \cdot \frac{\left(\mathrm{c}_{2}^{2}+1\right)}{\left(\mathrm{c}_{2}^{2}-1\right)}=249.89 \\
& \sigma_{\text {omin }}=\mathrm{P}_{\mathrm{S}} \cdot \frac{\left(\mathrm{c}_{2}{ }^{2}+1\right)}{\left(\mathrm{c}_{2}{ }^{2}-1\right)}=72.879
\end{aligned}
$$

\section{Validation by FEA}

The inner and outer cylinders are modeled in Design Modeler of Ansys Workbench 10 with the computed dimensions. The model is meshed by using brick elements. The contact elements are generated at the interface. The inside surface of inner cylinder is subjected to a fluid pressure of $250 \mathrm{~N} / \mathrm{mm} 2$. Here constraining the model is not required as the forces acting on the model are balanced. To avoid rigid body motion, weak spring forces in appropriate directions are applied by the software. By using nonlinear solver in Ansys Workbench FEA software, the results are obtained. They are as shown in Figures 7 to 12 and tabulated in Tables 1 to 3 . 


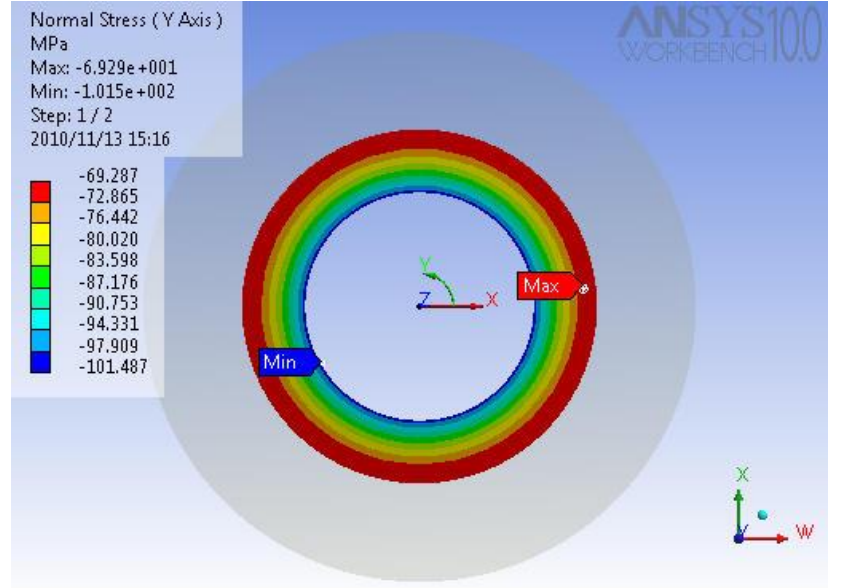

Figure 7. Minimum hoop stress contours - inner cylinder (without internal pressure).

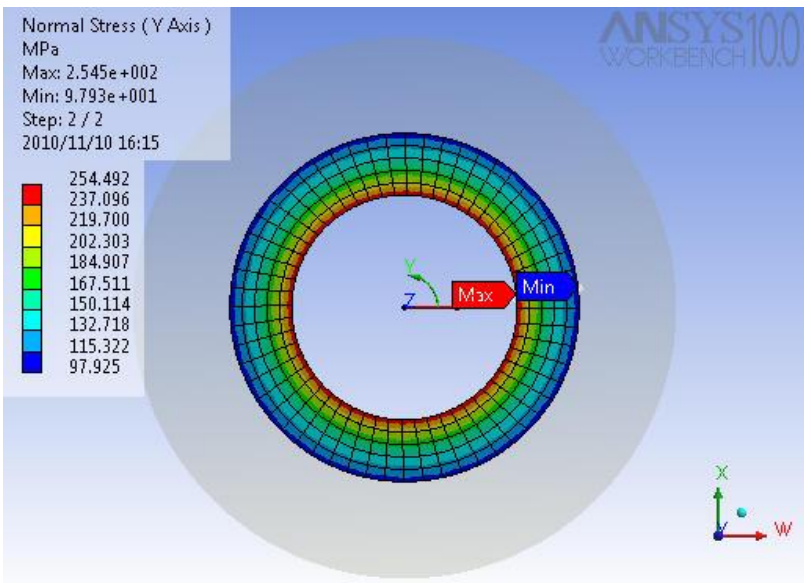

Figure 8. Maximum hoop stress contours - inner cylinder (with internal pressure).

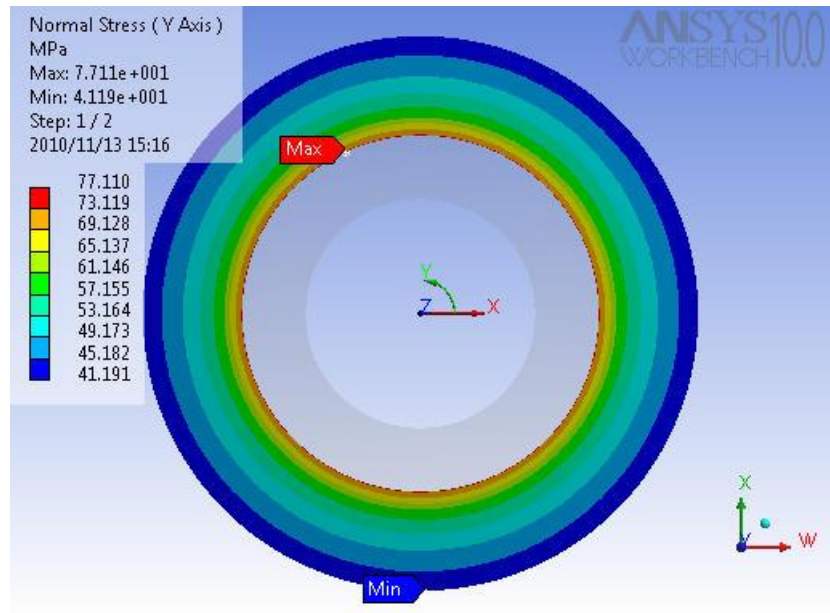

Figure 9. Maximum hoop stress contours - outer cylinder (without internal pressure).

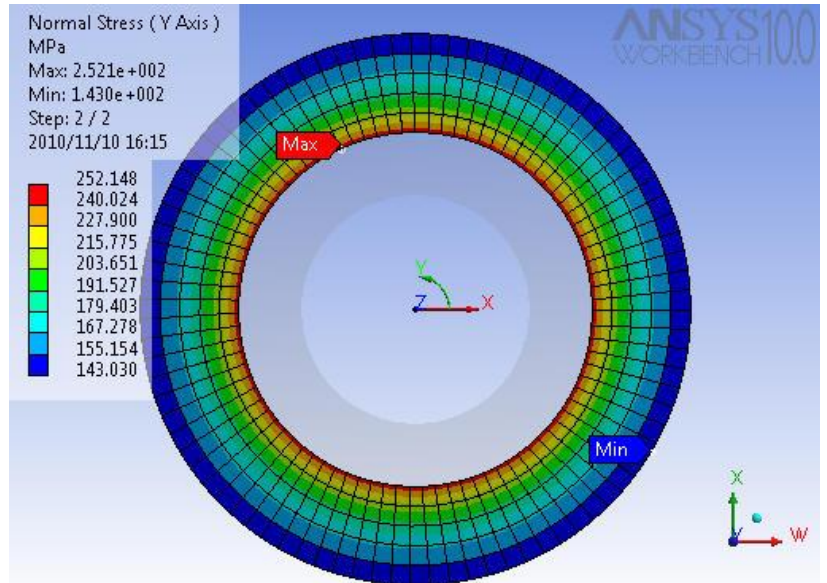

Figure 10. Maximum hoop stress contours - outer cylinder (with internal pressure).

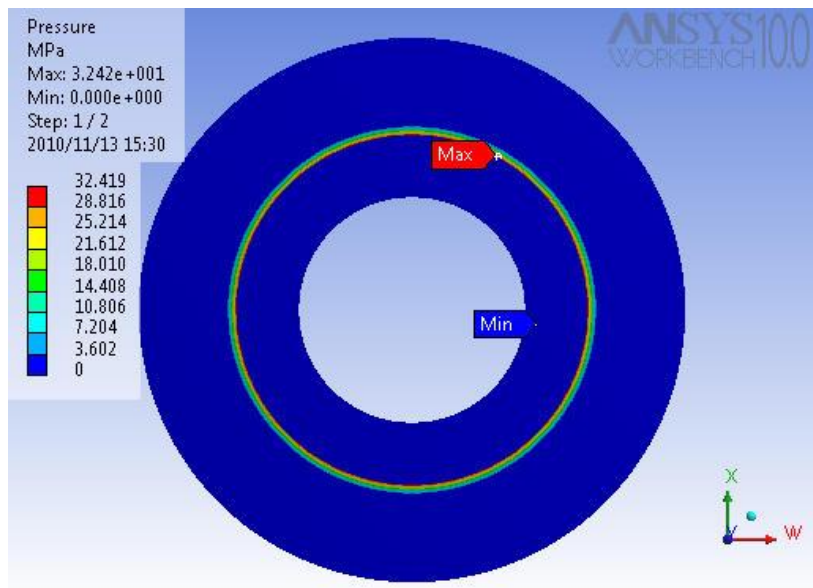

Figure 11. Contact pressure contours (without internal pressure).

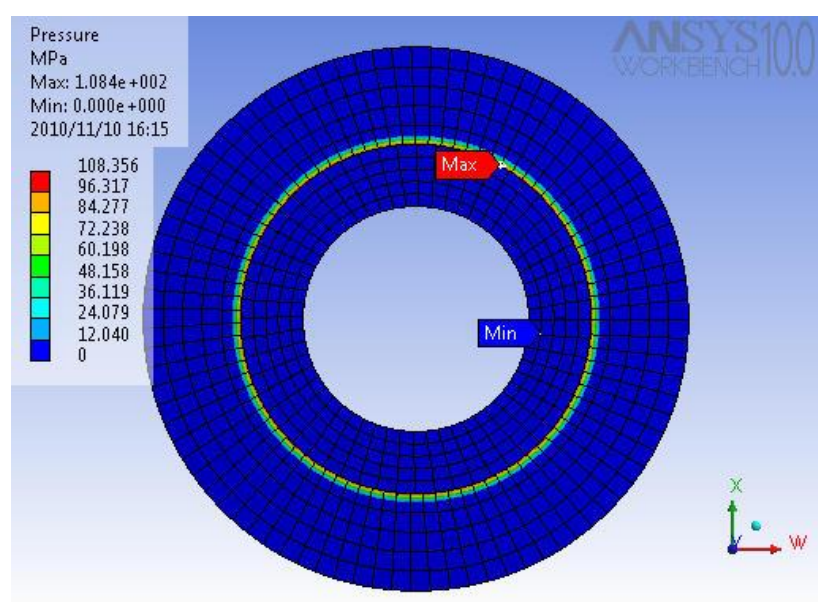

Figure 12. Contact pressure contours (with internal pressure). 
Table 1. Optimization results.

\begin{tabular}{cccc}
\hline $\mathbf{d}_{1}$ & $\mathbf{d}_{2}$ & $\mathbf{d}_{3}$ & $\boldsymbol{\delta}_{1}$ \\
\hline $100 \mathrm{~mm}$ & $155.22 \mathrm{~mm}$ & $241.5 \mathrm{~mm}$ & $0.108 \mathrm{~mm}$ \\
\hline
\end{tabular}

Table 2. Absolute maximum hoop stress.

\begin{tabular}{lcccc}
\hline \multirow{2}{*}{ Parameter } & \multicolumn{2}{c}{$\begin{array}{c}\text { Absolute maximum hoop stress } \\
\text { without internal pressure (0 MPa) }\end{array}$} & \multicolumn{2}{c}{$\begin{array}{c}\text { Absolute maximum hoop stress with } \\
\text { internal pressure ( 250 MPa) }\end{array}$} \\
\cline { 2 - 5 } & Exact & FEA & Exact & FEA \\
\hline Inner cylinder & -103.55 & -101.5 & 250 & 254.5 \\
Outer cylinder & 72.88 & 77.11 & 250 & 256.15 \\
\hline
\end{tabular}

Table 3. Contact pressure.

\begin{tabular}{|c|c|c|}
\hline \multirow{2}{*}{ Parameter } & \multicolumn{2}{|c|}{ Contact pressure (MPa) } \\
\hline & Exact & FEA \\
\hline Without internal pressure & 30.27 & 32.4 \\
\hline With internal pressure & 103.8 & 108.3 \\
\hline
\end{tabular}

\section{RESULTS AND CONCLUSION}

The values in Tables 1 to 3 indicate that the theoretical and FEA results are matching within $5 \%$ accuracy.

The compound cylinder is optimized for minimum volume (or weight) based on maximum tensile stress developed in both the cylinders. An iterative solver was used to find the optimum design parameters - the interface diameter, outside diameter and the diameterwise interference between the cylinders. The results obtained by numerical optimization were confirmed by manual calculations and verified by Ansys Workbench 10 finite element code. The results obtained by finite element analysis are matching very closely (within $5 \%$ error level) with the theoretical results. Recently the accuracy of finite element software has improved many folds, thus avoiding the need for physical prototype testing.

\section{Nomenclature}

$\mathbf{d}_{1}$, Inner diameter of compound cylinder; $\mathbf{d}_{2}$, Interface diameter of compound cylinder; $\mathbf{d}_{3}$, Outer diameter of compound cylinder; $\mathbf{P}$, internal pressure of the fluid; $\mathbf{P}_{\mathbf{s}}$, Contact pressure due to shrink fit; $\mathbf{P}_{\mathbf{s} 1}$, Contact pressure due to internal pressure; $\boldsymbol{\delta}_{1}$, Interference at the interface diameter; $\mathbf{E}$, Modulus of elasticity; $\boldsymbol{\sigma}_{\mathrm{t}}$, Max. permissible tensile (hoop) stress; $\boldsymbol{\mu}$, Poisson's ratio; $\mathbf{c}_{1}, \mathrm{~d}_{2} / \mathrm{d}_{1} ; \mathbf{c}_{2}, \mathrm{~d}_{3} / \mathrm{d}_{2}$ $\sigma_{\text {imax, }}$ Max Principal Stress in Inner Cylinder, $\sigma_{\text {omax, }}$ Max Principal Stress in Outer Cylinder; $\sigma_{\text {imin }}$, Minimum Principal Stress in Inner Cylinder; $\sigma_{\text {omin, Minimum }}$ Principal Stress in Outer Cylinder; V, Volume of fluid to be stored.

\section{REFERENCES}

Hojjati MH, Hassani A (2007). Theoretical and finite-element modeling of autofrettage process in strain-hardening thick-walled cylinders. Int. J. Press. Vessels Piping 84(5):310-319.

http://ansys.net/.

http://www.ansys.com/Resource.

Majzoobi GH, Farrahi GH, Mahmoudi AH (2003). A finite element simulation and an experimental study of autofrettage for strain hardened thick-walled cylinders. Mater. Sci. Eng. 359(1-2):326-331.

Majzoobi GH, Farrahi GH, Pipelzadeh MK, Akbari K (2004), Experimental and finite element prediction of bursting pressure in compound cylinders. Int. J. Press. Vessels Piping 81(12):889-896..

Majzoobi GH, Ghomi A (2006). "Optimization of Compound Pressure Cylinders". J. Achiev. Mater. Manuf. Eng. 15(1-2):135-145.

Ping X, Jinyang Z, Honggang C, Pengfei L (2010). "Optimal design of high pressure hydrogen storage vessel using an adaptive genetic algorithm." Int. J. Hydrogen Energy 35(7):2840-2846. 